Review

\title{
Chromatin Fiber Dynamics under Tension and Torsion
}

\section{Christophe Lavelle $^{1, *}$, Jean-Marc Victor ${ }^{2}$ and Jordanka Zlatanova ${ }^{3, *}$}

1 Interdisciplinary Research Institute, CNRS USR 3078, Villeneuve d'Ascq F-59655, France

2 Laboratoire de Physique Théorique de la Matière Condensée, CNRS UMR 7600, Paris F-75005, France

3 Department of Molecular Biology, University of Wyoming, Laramie, WY 82071, USA

* Authors to whom correspondence should be addressed;

E-Mails: christophe.lavelle@iri.univ-lille1.fr (C.L.); jordanka@uwyo.edu (J.Z.).

Received: 3 December 2009; in revised form: 20 February 2010 / Accepted: 19 March 2010 /

Published: 12 April 2010

\begin{abstract}
Genetic and epigenetic information in eukaryotic cells is carried on chromosomes, basically consisting of large compact supercoiled chromatin fibers. Micromanipulations have recently led to great advances in the knowledge of the complex mechanisms underlying the regulation of DNA transaction events by nucleosome and chromatin structural changes. Indeed, magnetic and optical tweezers have allowed opportunities to handle single nucleosomal particles or nucleosomal arrays and measure their response to forces and torques, mimicking the molecular constraints imposed in vivo by various molecular motors acting on the DNA. These challenging technical approaches provide us with deeper understanding of the way chromatin dynamically packages our genome and participates in the regulation of cellular metabolism.
\end{abstract}

Keywords: DNA; nucleosome; chromatin; single molecule; magnetic tweezers; optical tweezers

\section{Introduction}

A primordial question in biology today is: how does DNA regulate its own metabolism in general, and transcription in particular? In other words, where is the regulatory information that enables specific genes to be transcribed while others are silenced? Chromatin inevitably holds a significant part of the answer. DNA is indeed not naked in vivo but is associated, mainly with histones, to form a 
nucleoprotein complex whose structure and dynamics participate in the regulation of various DNA transaction events, including replication, transcription, repair and recombination (Figure 1). Singlemolecule approaches have recently complemented conventional biochemical and biophysical techniques and appeared as powerful tools to decipher the complex mechanisms ruling chromatin function and dynamics [1-3]. In these approaches, individual nucleosomes or chromatin fibers are investigated one-at-a-time through manipulation with different micro-systems. Here, we will mainly focus on results obtained via magnetic tweezers (MT) and optical tweezers (OT) [4]. Thanks to these techniques, we now have access to dynamic events that tend to be blurred when using traditional biochemical bulk experiments [5,6]. Furthermore, we can study one molecule at-a-time, thus gaining insights into the behavior of non-homogeneous specimens, whereas usual biochemical and biophysical techniques measure only the average behavior of the members of a population.

Figure 1. Molecular microscopy views of chromatin fibers. (a) Transmission Electron Microscopy (TEM) image of a nucleosomal array extracted from Chinese hamster ovary cells, spread in water and observed in annular darkfield mode after uranyl acetate staining (bar $100 \mathrm{~nm}$ ); adapted from [7]. Insert: nucleosome crystal structure (from 1kx5 PDB coordinates). (b) Atomic Force Microscopy (AFM) image of unfixed chromatin fibers extracted from chicken erythrocytes and spread on glass in low ionic strength buffer (imaged area $600 \times 600 \mathrm{~nm}$ ); adapted from [8].
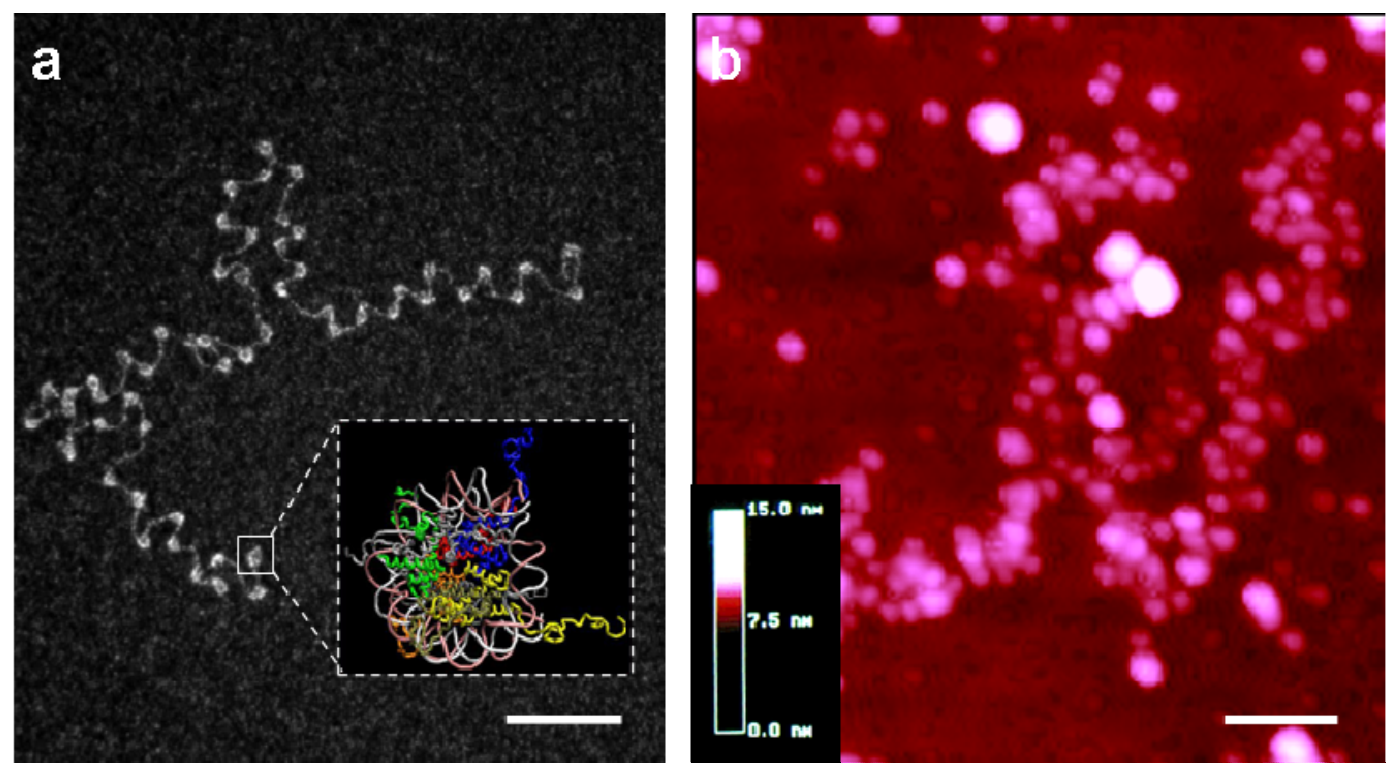

Since this field is quite recent, we will try to draw an almost exhaustive landscape of the many insights into chromatin structure and dynamics that were obtained by these techniques. Note, however, that for the scope of this focused review, we will only describe papers dealing with "conventional" chromatin (i.e., DNA compacted by histones), although fascinating results have also been obtained with other DNA-condensation mediators such as protamine in sperm chromatin [9], Abf2p in mitochondrial chromatin [10], or HU and H-NS in bacterial chromatin [11,12]. With the growing popularity of single-molecule approaches, more and more labs should soon be equipped with sophisticated instrumentation enabling investigation of structure, dynamics, forces and motions at the 
same time $[13,14]$. There is no doubt that the chromatin field has, and will further, benefit from this trend, hopefully uncovering some of the remaining mysteries of this "DNA manager".

\section{Nanotweezers: A New Tool to Handle Macromolecular Complexes}

Since first introduced to biological research about 15 years ago, single-molecule manipulation techniques have progressively broadened their application range and appear now as sensitive and versatile tools to study molecular mechanisms [5].

Figure 2. Various methods have been developed to manipulate single nucleosomal arrays. Depending on the setup, these experiments enable the study of nucleosome assembly/disassembly under constraints, to apply force (tension) and/or torque (torsion) on chromatin fibers and measure their mechanical response. These techniques use either OT (a,b), MT (c,d), flow (d,e) or the cantilever of an AFM (f) to apply constraints to a chromatin fiber attached at the other end to the surface of a cover slip (a,c,d,f) or to the extremity of a micropipette (b,e). Chromatin can thus be pulled (a,b,c,d,e,f) and rotated (c). $\mathrm{a}, \mathrm{b}$, and $\mathrm{f}$ are position clamps, while c, $\mathrm{d}$, and e can be used as both force or position clamps.

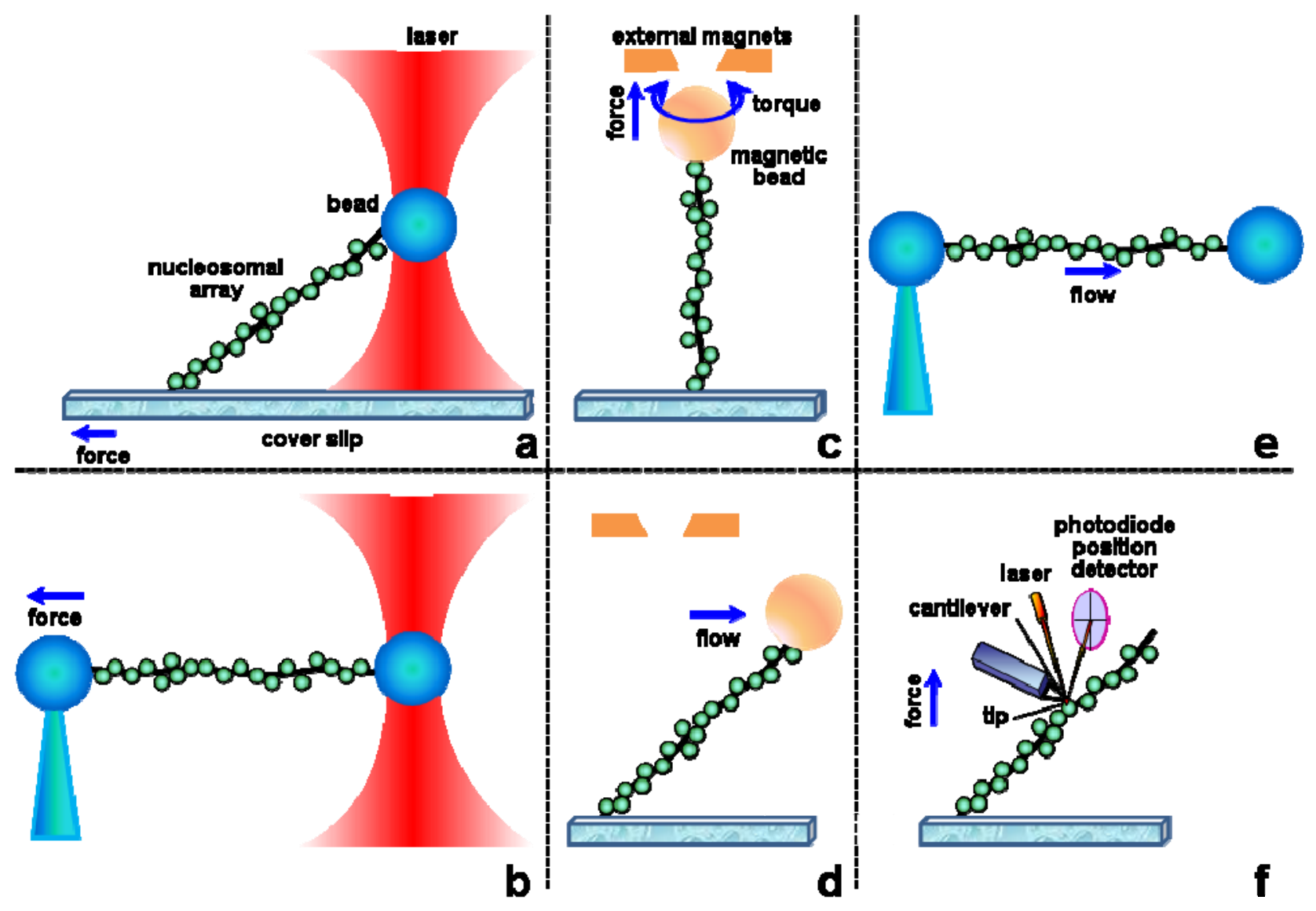

Biologically relevant forces vary from picoNewtons ( $\mathrm{pNs}$ ) (thermal fluctuation, entropic forces) to tens of pNs (produced by some powerful molecular motors, such as RNA polymerases). Molecular bonds span a few pNs for weak bonds (van der Waals, hydrogen and ionic bonds) to hundreds of pNs 
for covalent bonds. Note that antigen/antibody interaction forces are estimated at 100-250 pN [15], even though they rely only on weak bonds (working in parallel). Various tools have been developed that can exert and/or measure such forces at the single-molecule level, mainly mechanical force transducers (atomic force microscope cantilevers, microneedles, optical fibers) and external field (photonic in optical tweezers, magnetic in magnetic tweezers, hydrodynamic in flow field systems) manipulators [1,16-18] (Figure 2). In typical experiments, one investigates DNA or nucleosomal templates one-at-a-time, either by physically exerting forces and measuring subsequent deformation of the substrate or by using DNA as a mechanosensor to measure DNA-protein interactions. These devices are of two different kinds: position clamps, where one imposes the position of the object and measures the force needed to do so (AFM, microneedles and optical tweezers) and force clamps, where a constant force is applied and the extension of the molecule is measured (magnetic tweezers, hydrodynamic flow). Note that AFM and OT can be operated in both modes, the introduction of a feedback enabling them to work as force clamps. Results obtained with optical and magnetic tweezers, the two most used systems, will be discussed here in more detail.

\subsection{Optical Tweezers (OT)}

Optical tweezers use a focused laser beam to physically hold and move microscopic dielectric beads. Ashkin and colleagues reported the first use of what is now commonly referred to as an optical trap: a tightly focused beam of light capable of holding microscopic particles stable in three dimensions [19]; see [20] for a recent overview of the physical principles behind optical tweezers. In the late 1980s, Ashkin and colleagues first applied the technology to the biological sciences, using it to trap individual tobacco mosaic virus particles, Escherichia coli bacteria and various eukaryotic cells [21,22]. Throughout the 1990s and afterwards, researchers like Carlos Bustamante and Steven Block pioneered the use of optical trap force spectroscopy to characterize molecular-scale biological motors [23]. The first application to chromatin fibers appeared in 2000 [24] and other insightful experiments rapidly followed (reviewed in $[25,26]$ ). "Chromatin optical tweezers" in PubMed now retrieves 20 references, only half of which are primary experimental papers actually dealing with nucleosomes or chromatin fibers.

\subsection{Magnetic Tweezers (MT)}

Magnetic tweezers use external magnets to physically pull/rotate microscopic paramagnetic beads to which one attaches DNA molecules or chromatin fibers. Typical applications are single-molecule micromanipulation and studies of force/torque-regulated processes. Forces are typically on the order of a few piconewtons. Due to their simple architecture, magnetic tweezers are one of the most popular and widespread biophysical techniques [27]. They were first used to handle a single DNA molecule and measure its elasticity [28] and response to torsion [29], before being applied to study single nucleosomal arrays [30,31]. "Chromatin magnetic tweezers" in PubMed now retrieves 15 references, of which a third are primary experimental papers actually dealing with chromatin fibers. 


\section{Chromatin Fiber Manipulation}

Tweezers provide a powerful technique to test the response of chromatin fibers to physiological levels of tension and/or torsion; the results from these studies greatly improved our knowledge of nucleosome structure and dynamics within chromatin fibers [32]. Table 1 summarizes the 25 or so papers published so far that address nucleosomal fiber dynamics using either flow forces, OT or MT experiments. These experimental approaches (and the use of the AFM) to manipulate fibers are depicted in Figure 2.

Table 1. A comprehensive outline of published chromatin single-molecule manipulations. This table spans roughly 10 years (and about 30 papers, in chronological order within each category) of nano-handling of individual nucleosomes or chromatin fibers.

\begin{tabular}{|c|c|c|}
\hline Ref. & Approach & Observation/conclusion \\
\hline \multicolumn{3}{|c|}{ Flow force experiments } \\
\hline [33] & $\begin{array}{l}\text { Fluorescence video-microscopy was } \\
\text { used to follow chromatin assembly } \\
\text { on individual DNA molecules } \\
\text { immersed in a cellular extract } \\
\text { (Figure } 2 \mathrm{~d} \text {, without the bead at the } \\
\text { end of DNA). }\end{array}$ & $\begin{array}{l}\text { DNA molecules were compacted within a few } \\
\text { seconds into fibers resembling native chromatin } \\
\text { fibers (as assessed by AFM imaging). }\end{array}$ \\
\hline [34] & $\begin{array}{l}\text { Kinetics of assembly on single DNA } \\
\text { molecules were studied by } \\
\text { fluorescence video-microscopy in } \\
\text { the presence of either Xenopus egg } \\
\text { extracts or purified histones with } \\
\text { chaperone Nap1 (Figure 2d, without } \\
\text { the bead at the end of DNA). }\end{array}$ & $\begin{array}{l}\text { The assembly rates differed by a factor of up to } 1000 \\
\text { for the same amount of histones depending on the } \\
\text { system used. Faster kinetics and higher packing ratios } \\
\text { were reached with extracts, presumably indicating a } \\
\text { role of additional components present in this system. }\end{array}$ \\
\hline \multicolumn{3}{|c|}{ Optical Tweezers (OT) experiments } \\
\hline [24] & $\begin{array}{l}\text { OT were used to stretch single } \\
\text { chicken erythrocyte chromatin fibers } \\
\text { (Figure } 2 b \text { ). }\end{array}$ & $\begin{array}{l}\text { A reversible condensation-decondensation transition } \\
\text { appeared at } 5-6 \mathrm{pN} \text {. This corresponds to an } \\
\text { internucleosomal attraction energy of } \sim 3 \mathrm{kT} \text {, } \\
\text { suggesting that the fiber can interconvert between } \\
\text { open and closed states at physiological ionic strength } \\
\text { just because of thermal fluctuation. At forces }>20 \mathrm{pN} \text {, } \\
\text { the fibers were modified irreversibly, probably } \\
\text { because of removal of nucleosomes from the DNA } \\
\text { template. }\end{array}$ \\
\hline
\end{tabular}


Table 1. Cont.

\begin{tabular}{|c|c|c|}
\hline Ref. & Approach & Observation/conclusion \\
\hline$[35,36]$ & $\begin{array}{l}\lambda \text { phage DNA molecules were } \\
\text { suspended between two polystyrene } \\
\text { beads, one held by a micropipette } \\
\text { and the other one by an optical trap } \\
\text { (Figure 2b). Chromatin was } \\
\text { assembled using Xenopus egg } \\
\text { extracts, which was removed before } \\
\text { stretching. }\end{array}$ & $\begin{array}{l}\text { DNA apparent shortening revealed chromatin } \\
\text { assembly on the DNA template; assembly was } \\
\text { impeded by forces }>10 \mathrm{pN} \text {. Stretching of the } \\
\text { assembled chromatin fiber at forces }>20 \mathrm{pN} \text { revealed } \\
\text { sudden drops in force reflecting discrete opening } \\
\text { events of } \sim 65 \mathrm{~nm} \text { length, attributed to unwrapping of } \\
\text { nucleosomes (Figure } 3 \text { ). }\end{array}$ \\
\hline [37] & $\begin{array}{l}\text { OT were used to stretch nucleosomal } \\
\text { arrays reconstituted on DNA } \\
\text { fragments containing } 17 \text { direct } \\
\text { tandem repeats of a } 5 \mathrm{~S} \text { sequence } \\
\text { (Figure 2a). }\end{array}$ & $\begin{array}{l}\text { Forced disassembly of each nucleosome occurred in } \\
\text { three stages, corresponding to the successive } \\
\text { unwrapping of the two turns of DNA followed by } \\
\text { complete loss of the histone octamer (Figure } 3 \text { ). }\end{array}$ \\
\hline [38] & $\begin{array}{l}\text { OT were used to examine the } \\
\text { contributions of histone tails to } \\
\text { nucleosomal stability (Figure } 2 a \text { ). }\end{array}$ & $\begin{array}{l}\text { Enzymatic removal of histone tails as well as their } \\
\text { acetylation weakened the histone-DNA interactions } \\
\text { leading to partial DNA unwrapping. }\end{array}$ \\
\hline [39] & $\begin{array}{l}\text { OT were used to stretch native and } \\
\text { reconstituted nucleosomal arrays at } \\
\text { various concentrations (Figure } 2 \mathrm{~b} \text { ). }\end{array}$ & $\begin{array}{l}\text { Stretching a single chromatin fiber in very dilute } \\
\text { solutions showed } \sim 25 \mathrm{~nm} \text { discrete disruption length } \\
\text { (interpreted as } \mathrm{H} 2 \mathrm{~A}-\mathrm{H} 2 \mathrm{~B} \text { dimers release), whereas a } \\
\text { second } \sim 50 \mathrm{~nm} \text { length was observed at high } \\
\text { chromatin concentration (interpreted as full } \\
\text { nucleosome disruption). These results demonstrate } \\
\text { that nucleosome stability highly depends on } \\
\text { experimental conditions (sample concentration). }\end{array}$ \\
\hline$[40]$ & 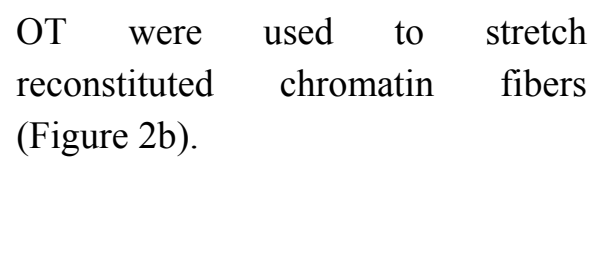 & $\begin{array}{l}\text { Fiber length increase per unbinding event showed } \\
\text { discrete values of } \sim 30 \mathrm{~nm} \text { and } \sim 60 \mathrm{~nm} \text {. Loading rate } \\
\text { analysis of the disruption forces revealed three } \\
\text { individual energy barriers ( } \sim 20,25 \text { and } 28 \mathrm{kT}) \text {, with } \\
\text { no apparent correlation with DNA length release. }\end{array}$ \\
\hline$[41]$ & $\begin{array}{l}\text { OT were used to monitor } \\
\text { nucleosome disassembly from a } \\
\text { regular nucleosomal array } \\
\text { preassembled in the presence of } \\
\text { Nap1 and chromatin remodeling } \\
\text { factor ACF (Figure 2b). }\end{array}$ & $\begin{array}{l}\text { Abrupt events releasing } \sim 55-95 \text { bp of DNA were } \\
\text { observed at a wide range of unravelling force } \\
(\sim 5-65 \mathrm{pN}) \text {, suggesting a strong dependence on the } \\
\text { DNA sequence within individual nucleosomes. This } \\
\text { variability in nucleosomal strength and the occurrences } \\
\text { of sudden DNA re-wrapping events is thought to have } \\
\text { an important regulatory influence on the binding of } \\
\text { transcription factors and the movement of polymerase } \\
\text { complexes on chromatin. }\end{array}$ \\
\hline
\end{tabular}


Table 1. Cont.

\begin{tabular}{|c|c|c|}
\hline Ref. & Approach & Observation/conclusion \\
\hline$[42]$ & $\begin{array}{l}\text { Chromatin fibers purified from HeLa } \\
\text { cells were tethered between a } \\
\text { microscope coverslip and a glass } \\
\text { micropipette. An intensity- } \\
\text { modulated optically trapped bead } \\
\text { positioned as a force sensor on the } \\
\text { chromatin fiber was used to measure } \\
\text { chromatin local fluidity (as inferred } \\
\text { from the phase standard deviation of } \\
\text { the bead oscillating in close contact } \\
\text { to the chromatin fiber). }\end{array}$ & $\begin{array}{l}\text { An initial increase in the local fluidity (triggered by } \\
\text { tension or enzymatic digestion of the histone tails) } \\
\text { preceded chromatin decompaction, suggesting possible } \\
\text { mechanisms by which chromatin-remodeling factors } \\
\text { access regulatory sites. }\end{array}$ \\
\hline [43] & $\begin{array}{l}\text { Using OT, individual DNA duplexes } \\
\text { containing a uniquely positioned } \\
\text { nucleosome flanked by long } \\
\text { segments of DNA were unzipped to } \\
\text { probe histone-DNA interactions and } \\
\text { SWI/SNF remodeling activity (setup } \\
\text { modified from that shown in } \\
\text { Figure 2a). }\end{array}$ & $\begin{array}{l}\text { Nucleosomes remodeled by SWI/SNF were moved } \\
\text { bidirectionally with a characteristic distance of motion } \\
\text { of } \sim 28 \text { bp per remodeling event. }\end{array}$ \\
\hline [44] & $\begin{array}{l}\text { OT were used to examine the force- } \\
\text { induced dynamic behavior of a } \\
\text { single nucleosome reconstituted on } \\
\text { the } 601 \text { positioning sequence } \\
\text { (Figure } 2 \mathrm{~b} \text { ). }\end{array}$ & $\begin{array}{l}\text { Nucleosome unravelled in at least two major stages: } \\
\text { the first attributed to unravelling of the first (outer) } \\
\text { DNA wrap around the histone octamer, the second to } \\
\text { the inner DNA wrap. }\end{array}$ \\
\hline [45] & $\begin{array}{l}\text { OT were used to monitor the activity } \\
\text { of RSC and SWI/SNF remodeling } \\
\text { factors on single nucleosomal } \\
\text { templates made from DNA } \\
\text { containing 5-9 tandem repeats of the } \\
601 \text { positioning sequence } \\
\text { (Figure 2b). }\end{array}$ & $\begin{array}{l}\text { Remodelers translocated along DNA at } \sim 13 \mathrm{bp} / \mathrm{s} \text { and } \\
\text { generated forces up to } \sim 12 \mathrm{pN} \text {, producing DNA loops } \\
\text { of } 20-1200 \text { bp (average } \sim 100 \mathrm{bp} \text { ). This behavior } \\
\text { differed significantly from that observed on bare } \\
\text { DNA [46], suggesting a nucleosome-specific activity } \\
\text { of RSC and other remodeling factors of the Swi } 2 / \mathrm{Snf} 2 \\
\text { family. }\end{array}$ \\
\hline [47] & $\begin{array}{l}\text { OT were used to unzip individual } \\
\text { DNA duplexes containing a uniquely } \\
\text { positioned nucleosome (setup } \\
\text { modified from that shown in } \\
\text { Figure 2a). }\end{array}$ & $\begin{array}{l}\text { A detailed map of histone-DNA interactions was } \\
\text { obtained to near bp resolution, revealing a } \sim 5 \text { bp } \\
\text { periodicity superimposed by three regions of strong } \\
\text { interactions, the strongest being at the dyad. Unzipping } \\
\text { up to the dyad allowed recovery of a canonical } \\
\text { nucleosome upon relaxation of the DNA, but } \\
\text { unzipping beyond the dyad resulted in irreversible } \\
\text { removal of the histone octamer from DNA. }\end{array}$ \\
\hline
\end{tabular}


Table 1. Cont.

\begin{tabular}{|c|c|c|}
\hline Ref. & Approach & Observation/conclusion \\
\hline [48] & $\begin{array}{l}\text { OT were used to study the force- } \\
\text { extension behavior of alpha-satellite } \\
\text { DNA from African green monkey, } \\
\text { naked or organized as nucleosomes } \\
\text { (Figure } 2 \text { b). }\end{array}$ & $\begin{array}{l}\text { Nucleosomes were disrupted at higher forces as } \\
\text { compared with random DNA nucleosomes, suggesting } \\
\text { that structural properties of alpha-satellite DNA are } \\
\text { responsible for the relatively higher mechanical } \\
\text { stability of African green monkey centromeric } \\
\text { heterochromatin. }\end{array}$ \\
\hline [49] & $\begin{array}{l}\text { OT were used to follow individual } \\
\text { RNA polymerase II complexes as } \\
\text { they transcribe a piece of DNA } \\
\text { wrapped in a nucleosome (Figure } 2 \mathrm{~b} \text {, } \\
\text { but both beads are held by a laser). }\end{array}$ & $\begin{array}{l}\text { The presence of a nucleosome locally increased pause } \\
\text { density, slowed recovery from the pause, and reduced } \\
\text { pause-free velocity of Pol II. Transcription through a } \\
\text { nucleosome seems to involve transfer of the core } \\
\text { histones behind the transcribing polymerase via a } \\
\text { transient DNA loop. }\end{array}$ \\
\hline
\end{tabular}

\section{Magnetic Tweezers (MT) experiments}

[30] MT were used to study chaperonemediated chromatin assembly/ disassembly on single $\lambda$ phage DNA molecules in real time (Figure 2d).

[46] MT were used to monitor the extension of a single DNA molecule at low force $(\sim 0.3 \mathrm{pN})$ in the presence of RSC remodeling factor (Figure 2c).

[31] MT were used to study the mechanical response to torsion of single nucleosome arrays reconstituted on 36 tandem repeats of a $5 \mathrm{~S}$ sequence (Figure $2 \mathrm{c}$ ).

[50,51] MT were used to study the interaction between purified histones and a DNA molecule under tension.
The rate of assembly strongly depended on the exerted force, with almost total inhibition at forces $>10 \mathrm{pN}$. During assembly at high forces, occasional abrupt increases in fiber length were observed, clearly suggesting reversibility of the assembly process.

RSC causes transient shortening of DNA resulting from the formation of a negatively supercoiled loop. AFM images confirmed this model. Only naked DNAs, no nucleosomal susbtrates, were tested in this study.

Nucleosome arrays can reversibly accommodate a large amount of supercoiling without much change in length.

Tension determines the rate of DNA condensation. The time course of compaction was exponential at low histone concentration and became sigmoidal at high concentrations, reflecting a cooperative loading of histones onto DNA. Under large forces, histone-DNA complexes were disrupted in a discrete manner with a step size of $\sim 60 \mathrm{~nm}$. 
Table 1. Cont.

\begin{tabular}{|c|c|c|}
\hline Ref. & Approach & Observation/conclusion \\
\hline$[52]$ & $\begin{array}{l}\text { MT were used to study assembly of } \\
\text { chromatin on single DNA molecules } \\
\text { incubated in Xenopus egg extracts } \\
\text { (Figure 2b, with a magnetic trap } \\
\text { replacing the optical trap). }\end{array}$ & $\begin{array}{l}\text { Force-induced disassembly and opening-closing } \\
\text { fluctuations were observed, with a strong dependence } \\
\text { on ATP, suggesting that ATP hydrolysis plays a major } \\
\text { role in nucleosome rearrangements in vivo. }\end{array}$ \\
\hline [53] & $\begin{array}{l}\text { MT were used to study the mechanical } \\
\text { response to torsion of single } \\
\text { nucleosomes or tetrasome arrays } \\
\text { reconstituted on tandem repeats of a } 5 \mathrm{~S} \\
\text { sequence (Figure } 2 \mathrm{c} \text { ). }\end{array}$ & $\begin{array}{l}\text { Nucleosome fibers submitted to large positive torsion } \\
\text { transiently trapped one positive turn per nucleosome, } \\
\text { reflecting a chiral transition of the particle to a } \\
\text { metastable, right-handed form (interpretation based on } \\
\text { the existence of the previously documented right- } \\
\text { handed tetrasome). }\end{array}$ \\
\hline [54] & $\begin{array}{l}\text { MT were used to reveal molecular } \\
\text { interactions at sub-pN forces within } \\
\text { sub-saturated ( } 4 \pm 3 \text { nucleosomes on } 17 \\
\text { tandem repeats of a } 5 \mathrm{~S} \text { sequence) } \\
\text { reconstituted chromatin fibers (Figure 2c). }\end{array}$ & $\begin{array}{l}\text { When small }(\sim 1 \mu \mathrm{m}) \text { beads are used, the hysteresis } \\
\text { caused by viscous drag on the magnetic bead is } \\
\text { sufficiently reduced to reveal individual interactions } \\
\text { between nucleosomes. }\end{array}$ \\
\hline [55] & $\begin{array}{l}\text { MT were used to probe the mechanical } \\
\text { properties of } 167 \text { and } 197 \text { bp repeat length } \\
\text { arrays of } 25 \text { nucleosomes (Figure 2c). }\end{array}$ & $\begin{array}{l}\text { At forces up to } 4 \mathrm{pN} \text {, the } 30 \text {-nm fiber stretches like a } \\
\text { Hookian spring, resulting in a three-fold extension. } \\
\text { Together with a high nucleosome-nucleosome stacking } \\
\text { energy, this was interpreted as supporting a solenoid as } \\
\text { the underlying topology of the } 30 \text {-nm fiber (see section } \\
3.4 \text { below). Linker histones do not affect the length or } \\
\text { stiffness of the fiber, but stabilize its folding. Fibers } \\
\text { with a nucleosome repeat length of } 167 \text { bp are stiffer, } \\
\text { consistent with a two-start helical arrangement. }\end{array}$ \\
\hline$[56]$ & $\begin{array}{l}\text { MT were used to measure the force- } \\
\text { induced unwrapping of DNA from a } \\
\text { single nucleosome (Figure } 2 \mathrm{c} \text { ). }\end{array}$ & $\begin{array}{l}\text { Hidden Markov analysis, adopted for the nonlinear } \\
\text { force-extension of DNA, can readily resolve } \\
\text { unwrapping events that are significantly smaller than } \\
\text { the Brownian fluctuations. }\end{array}$ \\
\hline [57] & $\begin{array}{l}\text { Nucleosome assembly was conducted } \\
\text { on single topologically-constrained } \\
\text { DNA tethers using chicken erythrocyte } \\
\text { core histones and Nap1, under constant } \\
\text { low force (Figure 2c). In some } \\
\text { experiments, rotation of the external } \\
\text { magnetic field was used to relieve the } \\
\text { compensatory positive stress } \\
\text { presumably accumulating during } \\
\text { assembly. }\end{array}$ & $\begin{array}{l}\text { Only partial assembly was observed on the } \\
\text { topologically-constrained tethers, whereas much more } \\
\text { complete assembly occurred on nicked tethers or on } \\
\text { tethers whose superhelical stress was mechanically } \\
\text { relieved during the assembly process. The positive } \\
\text { supercoiling density that stalled assembly was } \\
\text { estimated at } 0.025-0.051 \text {. }\end{array}$ \\
\hline
\end{tabular}




\subsection{Chromatin Assembly/Disassembly}

The first single-molecule study of chromatin assembly was carried out by Viovy's group [33]. They used real-time video-microscopy to follow the shortening (as a consequence of DNA wrapping around the histone core that occurs during nucleosome formation) of a single $\lambda$-DNA molecule attached at one end to a glass surface, the other end being stretched by the flow of cell-free extracts in the chamber. Other approaches to address chromatin assembly have been setup by Bennink et al. [36] (Figure 2e) and Leuba et al. [30] (Figure 2d) by attaching a bead to the free extremity of the DNA/chromatin fragment for subsequent manipulation of the assembled fibers. These studies showed that the kinetics of assembly is dependent on the applied force; nucleosome formation is inhibited at forces $>10 \mathrm{pN}$.

Recently, nucleosome assembly has been studied on topologically-constrained DNA to more closely mimic the in vivo situation, where chromatin fibers are topologically constrained in loops [57]. Assembly was achieved using chicken erythrocyte core histones and histone chaperone Nap1. Only partial assembly was observed on the topologically-constrained DNA tethers, with much more complete assembly on unconstrained (nicked) DNA. To verify the hypothesis that the lack of full nucleosome assembly was due to compensatory accumulation of positive supercoiling in the rest of the template, experiments were performed in which the positive stress was mechanically relieved by rotating the external magnetic field; indeed, such rotation led to resumption of assembly. The positive supercoiling density that led to stalling of assembly was estimated to be in the range of $0.025-0.051$.

Chromatin disassembly under applied force has been mostly studied using optical tweezers [24,35,37,40,41] (Figure 2a,b) and only more recently with magnetic tweezers [31] (Figure 2c). Note that the first pulling studies on single chromatin fibers were done by AFM [58,59], but it turned out to be quite tricky to interpret due to interactions of the nucleosomes with the glass surface [4]. Indeed, saw-tooth patterns were observed in force-distance curves, similar to those expected from unravelling of individual nucleosomes (and later seen in OT experiments, see below). Careful analysis of the data, however, revealed that the drops in force observed were simply due to detachment of individual nucleosomes from the surface of the AFM cells [4]. Note that getting rid of such surface interaction artefacts is also one of the major issues in OT and MT experiments, particularly when playing with histones, which are highly positively charged, and thus very sticky to surfaces. One should be careful to check that discrete signals such as saw-tooth patterns or steps are not due to nucleosome desorption from the surface of the beads; this can usually be done by repeating the experiments at various forces and in various salt conditions, and also by adding naked DNA spacer at each end of the reconstituted nucleosome array (to prevent histone sticking to surfaces; see below). Finally, correspondence between the number of steps and the number of nucleosomes on one hand, and the step size and the nucleosomal DNA length on the other hand, is a good indication of the relevance of the experiment [31,35,37]. 
Figure 3. Force/extension curves and their interpretation (see experimental setup Figure 2a). (a) Force versus length response of a single chromatin fiber handled by an OT. The fiber was directly assembled in the flow cell of the instrument from a single $\lambda$ DNA molecule and Xenopus cell-free extracts: these contain all core histones but lack linker histones. A portion of the representative force curve (upper panel) is enlarged in the lower panel. The discontinuities in the curve correspond to unraveling of individual nucleosomes within the fiber. The blue curve represents the relaxation) response, which exhibited a naked DNA-like behavior [35]. (b) A schematic of the step-wise mechanical disruption of the nucleosomal particle (unpeeling of nucleosomal DNA from the histone core) as suggested by Brower-Toland et al. [37] (see also Table 1).

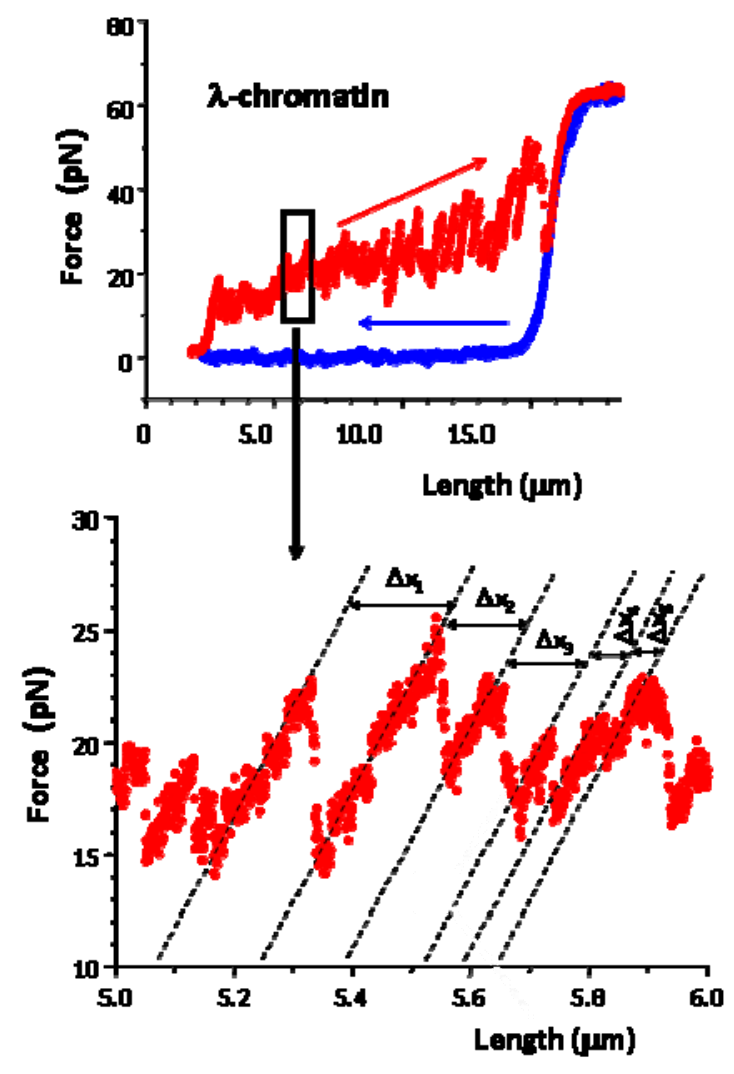

a

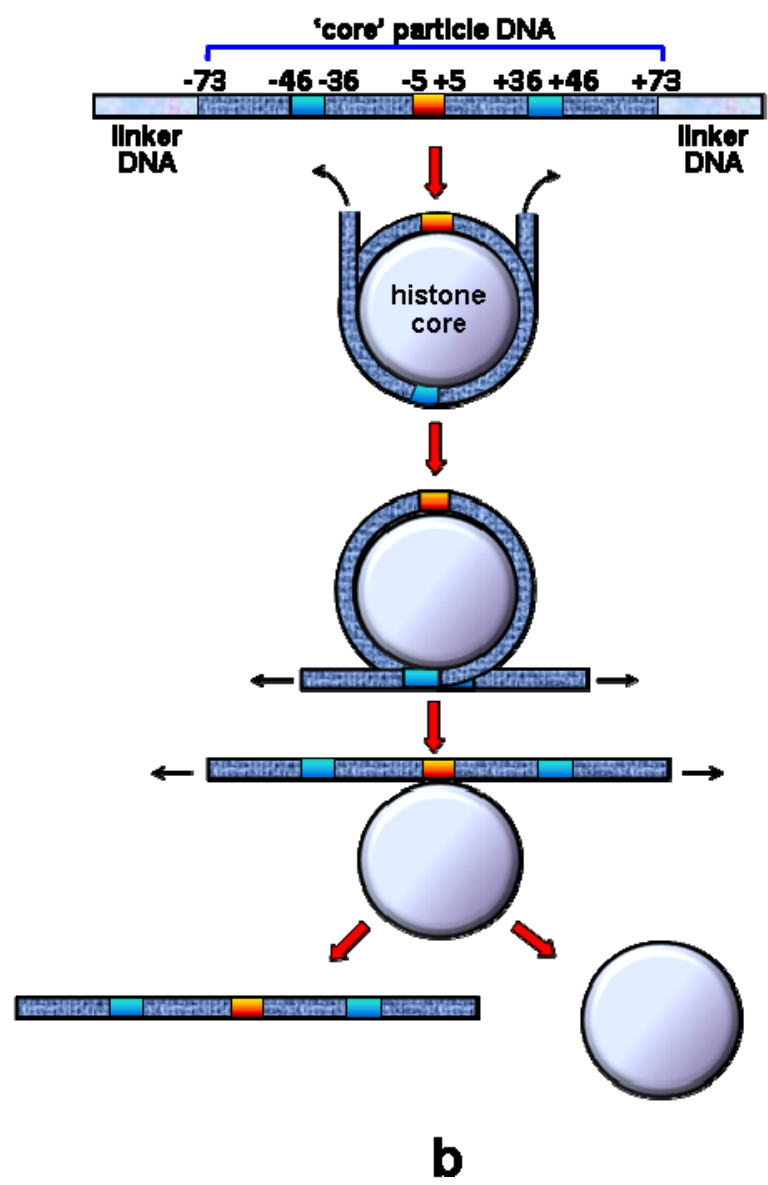

Force measurements in OT setups have revealed the existence of internucleosomal attraction that maintains the compacted chromatin structure under physiological condition [24]. These studies showed that, in the absence of any chromatin remodeling factors, the fibers undergo reversible stretching at forces $<\sim 20 \mathrm{pN}$ and irreversible unfolding at forces $>\sim 20 \mathrm{pN}[35,37,40]$. A step-wise release of the DNA/histone interactions was observed by Wang and colleagues [37] (Figure 3) and recently confirmed on single mononucleosomes [44]. Various chromatin remodelers use the energy of ATP hydrolysis to facilitate the process in vivo, lowering the unfolding energy barriers [31,41]. Finally, it was recently possible to measure, in DNA unzipping experiments, the relative strengths of the histone/DNA interactions along the length of nucleosomal DNA [47]. 


\subsection{Chromatin Topology}

Three years after Leuba/Zlatanova's MT studies of chromatin assembly, Bancaud et al. succeeded in using MT to apply torsion to single chromatin fibers, showing that chromatin can accommodate surprisingly large amount of torsional stress, either negative or positive, without much change in its extension [31,53]. In these two studies, nucleosome arrays were reconstituted on $2 \times 18$ tandem repeats of the $208 \mathrm{bp} 5 \mathrm{~S}$ nucleosome positioning sequence. They were subsequently ligated at each end to a naked DNA spacer (introduced into the construct to prevent histone sticking to surfaces) followed by a DNA sticker labeled appropriately for attachment of one end of the construct to the coated bottom of the flow cell and of the other end to a paramagnetic bead (Figures $2 \mathrm{c}$ ). The rotation of the magnets, hence of the paramagnetic bead, exerts torsion on the attached fiber. The fiber torsional behavior is described, at a given force, by its length-versus-rotation plot (Figure 4a).

The response of the corresponding naked DNA, obtained following salt dissociation of the histones, displays the signature of an intact (non-nicked) single duplex DNA. The central (plateau-like) part of the DNA response curve corresponds to the elastic regime, and the quasi-linear compactions on either side to the plectonemic regimes (formation of positive or negative plectonemes upon introduction of positive or negative rotations). The lower compaction on the negative side is due to a force-dependent DNA melting at high negative torsions, which prevents further increase of the torque on the molecule and prevents further plectoneme formation. Compared to DNA, chromatin is shorter and its center of rotation is shifted to negative values (see double arrow in Figure 4a). The shift is the expected consequence of the absorption of approximately one negative superhelical turn per nucleosome (actually $\Delta L k_{p} \approx-0.8 \pm 0.1$; see below), the observed shortening ( $\sim 50 \mathrm{~nm}$, i.e., $150 \mathrm{bp}$ per nucleosome) resulting from DNA wrapping around the histone core. Therefore, compared to DNA of the same length, the fiber in the elastic regime appears to be extremely torsionally flexible, i.e., it can absorb large amounts of torsion without much shortening. This large torsional resilience was interpreted as a reflection of the nucleosome dynamic equilibrium between the three conformational states previously identified in minicircles studies [60-62] (Figure 4c). More surprisingly, these chromatin fibers, after extensive positive supercoiling, display no nucleosome loss but rather a hysteretic behavior in their mechanical response to torsion [53] (Figure 4b). This hysteresis was interpreted as a consequence of the trapping of positive turns in individual nucleosomes through their transition to an altered form, originally called reversome (for reverse nucleosome) and later termed R-octasome (for right-handed nucleosome containing the full complement8-of histones) [63]. This structure is reminiscent of the previously documented R-tetrasome (a righthanded sub-nucleosomal particle containing only the $\mathrm{H} 3 / \mathrm{H} 4$ histone tetramer), which occurs as a result of a chiral transition of the tetrasome [64] (Figure 4d). 
Figure 4. Rotation/extension curves and their interpretation (see experimental setup in Figure 2c). (a) Length versus rotation response at $0.35 \mathrm{pN}$ of naked DNA (red), partially reconstituted (green) and saturated (blue) nucleosomal array. (b) Length versus rotation response of a saturated reconstituted nucleosomal array. Hysteresis is observed between the onward (blue) and backward (green) curves when a high positive torsion is applied [up to 70 positive turns, while torsion applied was less than 50 turns in (a)]; the zero-turn rotation reference corresponds to the relaxed state of naked DNA (red dotted curve). (c) The shortening, shifting and flattening of the curves in (a) is interpreted as the consequence of nucleosome reconstitution (each nucleosome wraps $\sim 50 \mathrm{~nm}$ of DNA in one negative superhelical turn) and conformational flexibility (threestate model) [31]. (d) The hysteresis observed at high torsion in (b) is interpreted as the consequence of a transient chiral transition of nucleosomes to an altered right-handed form [53].

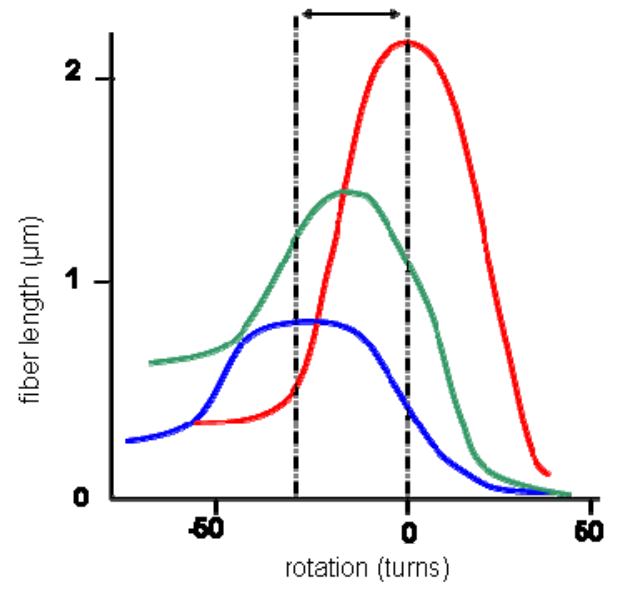

a

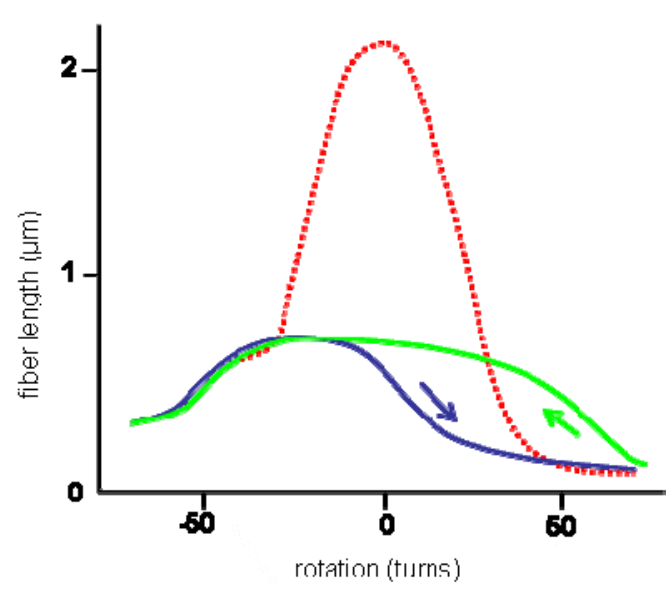

b
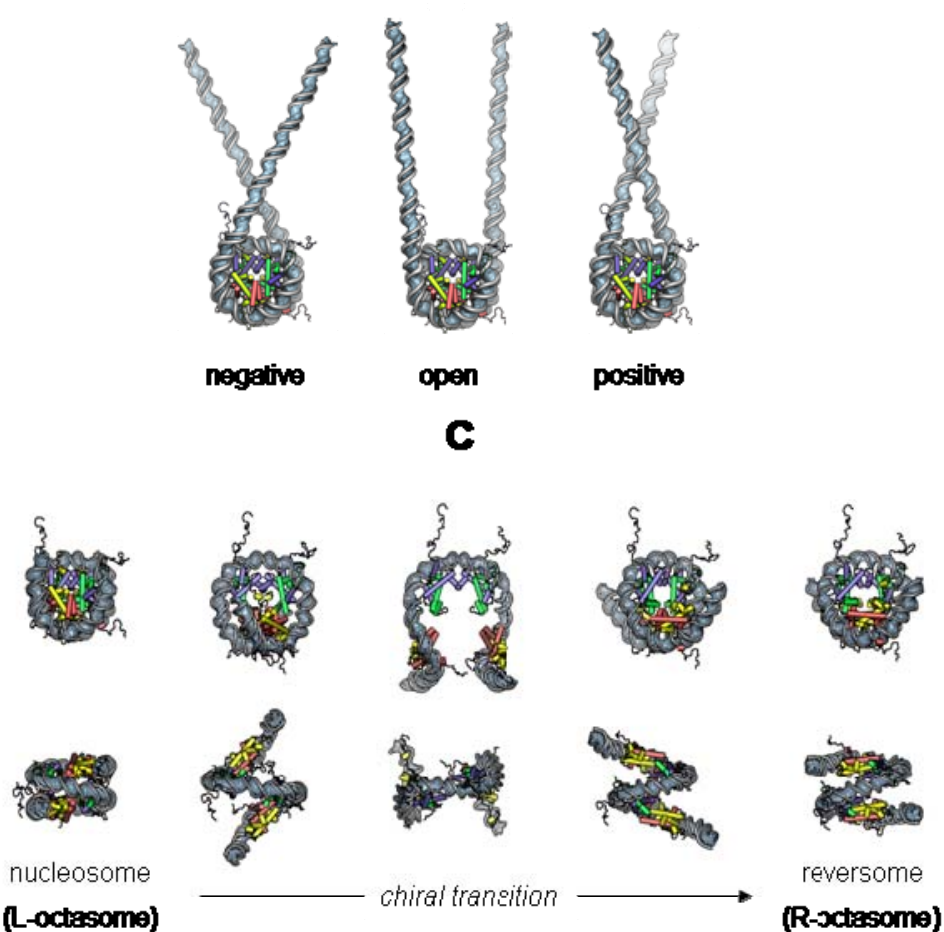

(R-xctasome) 


\subsection{Chromatin Mechanical Parameters}

To better characterize how the chromatin fiber may respond to mechanical constraints, some elastic parameters have to be determined, including bending flexibility, torsional flexibility and stretching modulus. Micromanipulation approaches coupled with modeling have been crucial in estimating these parameters both for DNA and chromatin. However, one should keep in mind that, beside divergences arising from experimental and data analysis differences, DNA sequence effects [65] and geometrical variability $[66,67]$ can greatly influence DNA and chromatin elastic parameters, respectively. Hence, the given values are mostly to be taken as orders of magnitude (Table 2). It is also worth noticing that, whereas forces are easily and precisely evaluated by OT as well as MT, torques remained more difficult to access $[68,69]$. The two devices can indeed be used to twist the molecule: in optical tweezers, light polarization is used to apply a torque, while in magnetic tweezers the magnetic field imposes the angular position of the molecule. In both cases, the torque in the range of pN.nm is far more difficult to measure than the stretching force. Remarkably, Sun and colleagues recently succeeded in measuring the torque exerted on a chromatin fiber by using a new MT setup that manipulates a ferromagnetic rod coupled to a magnetic bead in the field of a cylindrical magnet [70].

Table 2. Some approximate chromatin mechanical parameters.

\begin{tabular}{|c|c|c|c|c|}
\hline \multirow[t]{3}{*}{ Elastic constants } & & $\begin{array}{c}\text { Bending } \\
\text { persistence } \\
\text { length }(\mathrm{A})\end{array}$ & $\begin{array}{l}\text { Torsional } \\
\text { persistence } \\
\text { length }(\mathrm{C})\end{array}$ & $\begin{array}{l}\text { Stretching } \\
\text { modulus }(\sigma)\end{array}$ \\
\hline & DNA & $50 \mathrm{~nm}$ & $100 \mathrm{~nm}$ & $1,100 \mathrm{pN}$ \\
\hline & Chromatin & $30-200 \mathrm{~nm}$ & $5 \mathrm{~nm}$ & $5-8 \mathrm{pN}$ \\
\hline \multirow{2}{*}{$\begin{array}{l}\text { Destabilizing } \\
\quad \text { forces }\end{array}$} & \multicolumn{3}{|c|}{$\begin{array}{c}\text { Chromatin fiber unfolding } \\
\text { (compact } 30 \mathrm{~nm} \text { fiber to "beads on a string") }\end{array}$} & $<5 \mathrm{pN}$ \\
\hline & \multicolumn{3}{|c|}{$\begin{array}{l}\text { Nucleosome disruption } \\
\text { (DNA unwrapping from the surface of histone octamer) }\end{array}$} & $20 \mathrm{pN}$ \\
\hline
\end{tabular}

The persistence length of a polymer, A, a measure of bending flexibility (the smaller A, the more flexible), has been determined for DNA in various experiments, leading to a consensus value of $\sim 50 \mathrm{~nm}(150 \mathrm{bp})$ at physiological ionic strength [71,72]. The values for chromatin are more divergent, from $\sim 30-50 \mathrm{~nm}$ estimated from single-molecule stretching [24,31,35], recombination frequencies [73] or cross-linking probabilities [74] to more than $200 \mathrm{~nm}$ from recent in situ hybridization experiments [75]. Remarkably, such different values are all consistent with theoretical models and could be explained by polymorphic connection geometry between nucleosomes in the fiber $[66,67]$.

The torsional persistence length $\mathrm{C}$, a measure of twisting flexibility, has been estimated for naked DNA by various bulk experiments to be $\sim 70-100 \mathrm{~nm}(200-300 \mathrm{bp})$ [76,77]; this value is consistent with single-molecule data [29] analyzed through an elastic model [78]. The torsional persistence length of the chromatin fiber, measured only recently, has a surprisingly low value of $5 \mathrm{~nm}$ [31]; this is almost 20-times lower than that of naked DNA, and also lower than the value predicted from analytical models of chromatin fibers [66]. However, this unexpected experimental result is easily explained by 
the conformational nucleosome dynamics (see discussion above), and is fully consistent with new chromatin models that include this nucleosome property [31].

The stretching modulus $\sigma$, a measure of stretching elasticity (i.e., the propensity of a polymer to reversibly extend under a given tension - the smaller $\sigma$, the more extensible), is $\sim 1100 \mathrm{pN}$ for naked DNA, as estimated from single-molecule experiments [79-81]. For the chromatin fiber, a much lower value of $\sim 5-8 \mathrm{pN}$ has been derived from the same kind of experiments [24,31]; such value is close to the predicted one [66] and probably reflects the flexibility of the linkers as well as the weak internucleosomal interactions disrupted during the mechanical extension of the fiber at low ionic strength. Confirming this view, the stretching modulus is indeed greatly enhanced in high salt conditions where the fiber adopts a more compacted state $[35,82]$.

\subsection{Fiber Structure}

Whereas MT and OT provide a unique tool for probing the mechanical properties of DNA-protein complexes, in particular those of nucleosomes, they remain of little help in characterizing chromatin fiber structure. As a matter of fact, force-extension diagrams require an underlying model for their interpretation. Of note, the Hookian behavior of regular arrays of nucleosomes, recently evidenced by van Noort and colleagues, has been claimed by this group to match a solenoid structure for a 197-bp repeat length array structure but a zig-zag structure for 167-bp fiber [55]. In their model, they assumed a priori a solenoid structure for the 197-bp repeat length array from which they deduced a nucleosome-nucleosome stacking energy as large as $\sim 14 \mathrm{kT}$, despite the fact that nucleosomes are loosely stacked in their solenoid structure. This stacking energy is obtained by fitting the forceextension plots with a mechanical model involving eight parameters, five of which are free. In this model, the Hookian behavior is related to the elasticity of the disordered histone tails which are assumed to bridge the stacked nucleosomes, until they eventually break at forces $>3 \mathrm{pN}$ in absence of linker histone.

At odds with this modeling, an alternative interpretation has been proposed (Victor et al, submitted) that assumes a zig-zag structure for both 167-bp and 197-bp fibers [83,84]. In this model, the Hookian behavior is related to a gradual unwrapping of the nucleosomal DNA, by consecutively breaking the histone/DNA contacts at the Super Helix Locations: SHL \pm 6.5 , then SHL \pm 5.5 , and eventually $\mathrm{SHL} \pm 4.5$. Note that the Hookian behavior as well as the corresponding spring stiffness of the fibers, either 167-bp or 197-bp, are well fitted with the so-called "tunable spring" model [66], in which the fiber stiffness is completely determined by the fiber geometry and the linker DNA persistence length. There is only one free parameter, namely the free energy of the SHL \pm 5.5 .

\subsection{Chromatin Remodeling}

Remodeling has been also addressed using MT [46] and OT [43,45] (see [85] for a recent review). To date, only one family of remodelers has been studied by single-molecule manipulations, specifically the $S$. cerevisiae RSC and SWI/SNF complexes of the Swi2/Snf2 family. These remodelers are ATP-dependent DNA translocases. They contain two DNA-binding domains: one stationary tracking domain which remains in a fixed position relative to the histone octamer, and the other alternating between one of two conformations. The two domains bind the DNA at two different 
sites on the duplex, stabilizing a transient DNA loop, resulting in a temporary shortening of the molecule. Note that this shortening is what is monitored by MT. The inchworm-like action of both domains imparts DNA translocation.

The first single-molecule observation of DNA translocation by a remodeler has been performed in the group of Vincent Croquette and David Bensimon in collaboration with Tom Owen-Hughes [46]. Using MT with naked DNA, they observed at forces $<1 \mathrm{pN}$ that a single RSC complex causes transient shortening of the DNA, which results from the formation of a negatively supercoiled loop. At the same time, Bustamante's group used OT to monitor the action of both RSC and SWI/SNF complexes on single nucleosomes in real time [45]. This group worked at forces $>3 \mathrm{pN}$ in order to avoid loop formation within bare DNA; in this way they could study the translocase activity specifically related to nucleosome remodeling in isolation. Their setup gives access to the physical parameters associated with translocation except for the twist, namely speed, force and processivity. Importantly, DNA translocation has been observed to occur at constant speed under varying forces, suggesting that remodelers function as motors rather than as ratchets [76].

Figure 5. Nucleosome remodeling assessed by OT. (a) The nucleosome construct is attached to the bead by a biotin-streptavidin bond and to the coverslip by a digoxigenin-anti-digoxigenin linkage. The bead is kept fixed by tuning the laser power (optical trap) while coverslip is moving away from the bead, imparting the unzipping of the (in red) part of the dsDNA from the nick. (b) Plotting applied force (calibrated by laser power) versus number of base pairs unzipped provides a mapping of nucleosome position at single basepair resolution. The three curves are the results obtained with three different constructs: naked DNA (in black), tetrasome (in blue) and nucleosome (in red). After remodeling by SWI/SNF the nucleosome is moved away from its initial position. Repeating the experiment on a sample of $\sim 150$ nucleosomes results in a histogram of displacements, that is symmetrical around zero with a standard deviation of $28 \mathrm{bp}$.

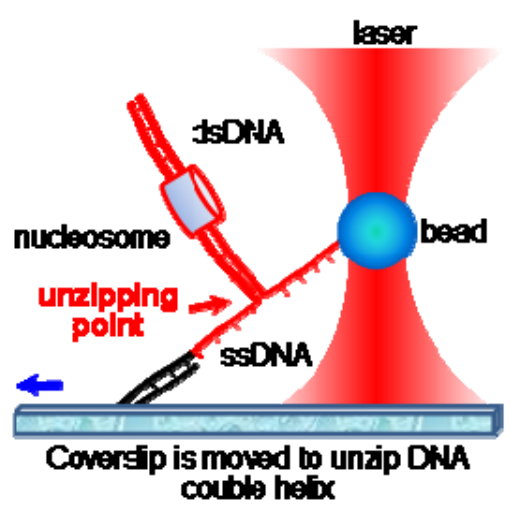

a

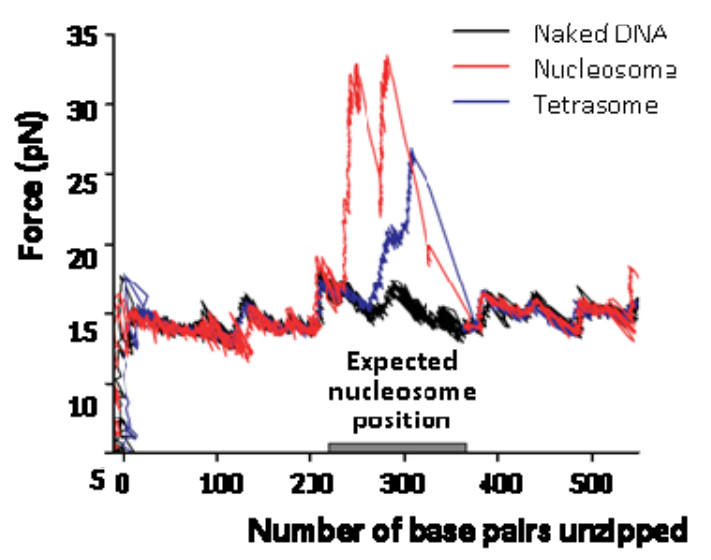

b

Wang's group recently used a sophisticated "unzipping" technique to analyse single nucleosome products after remodeling by SWI/SNF [43] (see Figure 5 for details). The general mechanism that emerges from these single-molecule studies is a "DNA inchworm" model involving both twist and 
loop propagation ( $\sim 1 \mathrm{bp}$ of twist for $10 \mathrm{bp}$ of translocation) [85]. This model explains why the displacements after remodeling that are measured by Wang's group are much smaller than the loop sizes measured by the other two groups. Indeed, the inchworm-like action of both DNA-binding domains generates large loops that are likely to be resorbed substantially before imparting DNA translocation. As a result, the displacements are expected to be much smaller than the loop sizes. Single-molecule studies with the three other families-Iswi, Nurd/Mi-2/Chd and Ino/Swr1-are anticipated, with a special attention to the ISWI complexes.

\section{Conclusion and Perspectives}

More than providing a "natural barrier" to DNA accessibility and compacting DNA, chromatin has functional roles that relevant experiments and models should help us to understand. Chromatin faces electrostatic, elastic and topological constraints that have to be integrated in multiscale models including both structural and dynamical parameters. The three-dimensional chromatin structure depends on distinct but highly coupled parameters: DNA sequence, nucleosome spacing (and the regularity of this spacing), histone modifications (through incorporation of histone variants and/or post-translational modifications), nucleosome conformation (through DNA fluctuations at the entry/exit sites and potential deformation of the core particle itself), interactions within the fiber (through histone tail interactions and DNA elasticity and topology) and non-histone proteins possibly present (i.e., HMG proteins, HP1 in heterochromatin, TRF1/2 in telomeres). Only recently, these issues are being addressed by single-molecule techniques, as seen from the comprehensive list of references in Table 1; 22 of the 28 total are less than five years old.

So, what did we learn from these studies that we did not know before? First, from a quantitative point of view, we got direct measurements of internucleosomal interactions, DNA/histone binding and unbinding steps, forces and torques produced by molecular motors acting on DNA (and how differently these motors behave on a chromatin template) and the response of chromatin fibers to these mechanical constraints. From a qualitative point of view, two main features should be retained from these studies: first, torsional and bending deformations are transmitted at about the same distances in DNA but not in chromatin, where torsional flexibility may be as much as 40 times higher than bending flexibility. Secondly, the stretching modulus being much greater (up to 200 times) for DNA than for chromatin, tension applied by a molecular motor on the DNA backbone will cause chromatin distortion well before DNA distortion. These features are undoubtedly valuable to understanding the function of chromatin in vivo. One should also acknowledge some frustrating limitations of these studies: so far, OT and MT experiments greatly improved our knowledge of nucleosome structure and dynamics within chromatin fibers, but failed to reveal chromatin structure/folding itself (e.g., the enigmatic and highly debated 3D structure of the so-called 30nm fiber).

Where should we go now? Chromatin is a polymorphic substrate, comprising nucleosomes and their more or less specific interactions influenced by DNA topology. Time has come to transpose the mechanistic approach to DNA considered as a "molecular spring"-which has proved valuable for the study of many biological processes, including DNA/protein recognition, nucleosome positioning and transcription initiation-to the next and more physiological structural level, i.e., the chromatin fiber. From a purely mechanistic point of view, the chromatin fiber may be regarded as a complex and 
polymorphic functional "supramolecular metaspring" (basically, a spring-the chromatin fiber-made of loops and spirals of another spring-the DNA molecule) [66]. In the quest of mechanistic understanding of transcriptional regulation, a detailed description of the nuclear architecture, with the function of its subcompartments, and of the genome organization is obviously required, along with the extent to which nuclear structural proteins (lamin, actin) influence higher-order chromatin structure and tissuespecific gene expression [32]. For this, single-molecule fluorescence spectroscopy [86] along with single-molecule manipulation in vivo $[87,88]$ is expected to provide exciting outcomes. At the same times, enzymatic processes (topological relaxation, transcription, DNA processing by molecular motors), that have been thoroughly studied on naked single DNA molecules, need to be investigated on their physiologically relevant substrate - single chromatin templates. The accumulation of new quantitative data (both in vitro and in vivo) and molecular models provided by these complementary approaches should help to drive us towards a more consistent and biologically relevant mechanistic view of genetic expression within the next years. The technological advances we have been witnessing during the past decade open new and exciting venues for research.

\section{Acknowledgements}

We are grateful to Hua Wong for help with Figure 4 and Vincent Croquette for fruitful comments on the manuscript. Work in Zlatanova's lab has been funded by National Science Foundation grant No. 0504239.

\section{References}

1. Zlatanova, J.; Leuba, S.H. Chromatin fibers, one-at-a-time. J. Mol. Biol. 2003, 331, 1-19.

2. Zlatanova, J.; Leuba, S.H. Stretching and imaging single DNA molecules and chromatin. $J$. Muscle Res. Cell Motil. 2002, 23, 377-395.

3. Chien, F.T.; van Noort, J. 10 years of tension on chromatin: Results from single molecule force spectroscopy. Curr. Pharm. Biotechnol. 2009, 10, 474-485.

4. Zlatanova, J.; Leuba, S. Chromatin structure and dynamics: Lessons from single molecule approaches. In Chromatin Structure and Dynamics: State-of-the-art; Zlatanova, J.; Leuba, S., Eds.; Elsevier: Amsterdam, Holland, 2004; pp. 369-396.

5. Bustamante, C. In singulo Biochemistry: When Less Is More. Annu. Rev. Biochem. 2008, 77, $45-50$.

6. Zlatanova, J.; van Holde, K. Single-molecule biology: What is it and how does it work? Mol. Cell 2006, 24, 317-329.

7. Mozziconacci, J.; Lavelle, C. Chromatin Fiber: 30 years of models. In Computational Biology: New Research; Russe, A.S., Ed.; Nova Science: New York, NY, USA, 2009; pp. 147-163.

8. Leuba, S.H.; Yang, G.; Robert, C.; Samori, B.; van Holde, K.; Zlatanova, J.; Bustamante, C. Three-dimensional structure of extended chromatin fibers as revealed by tapping-mode scanning force microscopy. Proc. Natl. Acad. Sci. USA 1994, 91, 11621-11625.

9. Brewer, L.R.; Corzett, M.; Balhorn, R. Protamine-induced condensation and decondensation of the same DNA molecule. Science 1999, 286, 120-123. 
10. Brewer, L.R.; Friddle, R.; Noy, A.; Baldwin, E.; Martin, S.S.; Corzett, M.; Balhorn, R.; Baskin, R.J. Packaging of single DNA molecules by the yeast mitochondrial protein Abf2p. Biophys. J. 2003, 85, 2519-2524.

11. Dame, R.T.; Noom, M.C.; Wuite, G.J. Bacterial chromatin organization by H-NS protein unravelled using dual DNA manipulation. Nature 2006, 444, 387-390.

12. van Noort, J.; Verbrugge, S.; Goosen, N.; Dekker, C.; Dame, R.T. Dual architectural roles of HU: Formation of flexible hinges and rigid filaments. Proc. Natl. Acad. Sci. USA 2004, 101, 6969-6974.

13. Neuman, K.C.; Nagy, A. Single-molecule force spectroscopy: Optical tweezers, magnetic tweezers and atomic force microscopy. Nat. Methods 2008, 5, 491-505.

14. Walter, N.G.; Huang, C.Y.; Manzo, A.J.; Sobhy, M.A. Do-it-yourself guide: How to use the modern single-molecule toolkit. Nat. Methods 2008, 5, 475-489.

15. Zlatanova, J.; Lindsay, S.M.; Leuba, S.H. Single molecule force spectroscopy in biology using the atomic force microscope. Prog. Biophys. Mol. Biol. 2000, 74, 37-61.

16. Bustamante, C.; Macosko, J.C.; Wuite, G.J. Grabbing the cat by the tail: Manipulating molecules one by one. Nat. Rev. Mol. Cell Biol. 2000, 1, 130-136.

17. Bustamante, C.; Bryant, Z.; Smith, S.B. Ten years of tension: Single-molecule DNA mechanics. Nature 2003, 421, 423-427.

18. Brewer, L.R.; Bianco, P.R. Laminar flow cells for single-molecule studies of DNA-protein interactions. Nat. Methods 2008, 5, 517-525.

19. Chu, S.; Bjorkholm, J.E.; Ashkin, A.; Cable, A. Experimental observation of optically trapped atoms. Phys. Rev. Lett. 1986, 57, 314-317.

20. Neuman, K.C.; Block, S.M. Optical trapping. Rev. Sci. Instrum. 2004, 75, 2787-2809.

21. Ashkin, A.; Dziedzic, J.M. Optical trapping and manipulation of viruses and bacteria. Science 1987, 235, 1517-1520.

22. Ashkin, A.; Dziedzic, J.M.; Yamane, T. Optical trapping and manipulation of single cells using infrared laser beams. Nature 1987, 330, 769-771.

23. Moffitt, J.R.; Chemla, Y.R.; Smith, S.B.; Bustamante, C. Recent advances in optical tweezers. Annu. Rev. Biochem. 2008, 77, 205-228.

24. Cui, Y.; Bustamante, C. Pulling a single chromatin fiber reveals the forces that maintain its higher-order structure. Proc. Natl. Acad. Sci. USA 2000, 97, 127-132.

25. Pope, L.H.; Bennink, M.L.; Greve, J. Optical tweezers stretching of chromatin. J. Muscle Res. Cell Motil. 2002, 23, 397-407.

26. Claudet, C.; Bednar, J. Pulling the chromatin. Eur. Phys. J. E Soft Matter 2006, 19, 331-337.

27. Meglio, A.; Praly, E.; Ding, F.; Allemand, J.F.; Bensimon, D.; Croquette, V. Single DNA/protein studies with magnetic traps. Curr. Opin. Struct. Biol 2009, 19, 615-622.

28. Smith, S.B.; Finzi, L.; Bustamante, C. Direct mechanical measurements of the elasticity of single DNA molecules by using magnetic beads. Science 1992, 258, 1122-1126.

29. Strick, T.R.; Allemand, J.F.; Bensimon, D.; Bensimon, A.; Croquette, V. The elasticity of a single supercoiled DNA molecule. Science 1996, 271, 1835-1837. 
30. Leuba, S.H.; Karymov, M.A.; Tomschik, M.; Ramjit, R.; Smith, P.; Zlatanova, J. Assembly of single chromatin fibers depends on the tension in the DNA molecule: Magnetic tweezers study. Proc. Natl. Acad. Sci. USA 2003, 100, 495-500.

31. Bancaud, A.; Conde e Silva, N.; Barbi, M.; Wagner, G.; Allemand, J.F.; Mozziconacci, J.; Lavelle, C.; Croquette, V.; Victor, J.M.; Prunell, A.; Viovy, J.L. Structural plasticity of single chromatin fibers revealed by torsional manipulation. Nat. Struct. Mol. Biol. 2006, 13, 444-450.

32. Lavelle, C. Forces and torques in the nucleus: Chromatin under mechanical constraints. Biochem. Cell Biol. 2009, 87, 307-322.

33. Ladoux, B.; Quivy, J.P.; Doyle, P.; du Roure, O.; Almouzni, G.; Viovy, J.L. Fast kinetics of chromatin assembly revealed by single-molecule videomicroscopy and scanning force microscopy. Proc. Natl. Acad. Sci. USA 2000, 97, 14251-14256.

34. Wagner, G.; Bancaud, A.; Quivy, J.P.; Clapier, C.; Almouzni, G.; Viovy, J.L. Compaction kinetics on single DNAs: Purified nucleosome reconstitution systems versus crude extract. Biophys. J. 2005, 89, 3647-3659.

35. Bennink, M.L.; Leuba, S.H.; Leno, G.H.; Zlatanova, J.; de Grooth, B.G.; Greve, J. Unfolding individual nucleosomes by stretching single chromatin fibers with optical tweezers. Nat. Struct. Biol. 2001, 8, 606-610.

36. Bennink, M.L.; Pope, L.H.; Leuba, S.H.; De Grooth, B.G.; Greve, J. Single chromatin fiber assembly using optical tweezers. Single Mol. 2001, 2, 91-97.

37. Brower-Toland, B.D.; Smith, C.L.; Yeh, R.C.; Lis, J.T.; Peterson, C.L.; Wang, M.D. Mechanical disruption of individual nucleosomes reveals a reversible multistage release of DNA. Proc. Natl. Acad. Sci. USA 2002, 99, 1960-1965.

38. Brower-Toland, B.; Wacker, D.A.; Fulbright, R.M.; Lis, J.T.; Kraus, W.L.; Wang, M.D. Specific contributions of histone tails and their acetylation to the mechanical stability of nucleosomes. J. Mol. Biol. 2005, 346, 135-146.

39. Claudet, C.; Angelov, D.; Bouvet, P.; Dimitrov, S.; Bednar, J. Histone octamer instability under single molecule experiment conditions. J. Biol. Chem. 2005, 280, 19958-19965.

40. Pope, L.H.; Bennink, M.L.; van Leijenhorst-Groener, K.A.; Nikova, D.; Greve, J.; Marko, J.F. Single chromatin fiber stretching reveals physically distinct populations of disassembly events. Biophys. J. 2005, 88, 3572-3583.

41. Gemmen, G.J.; Sim, R.; Haushalter, K.A.; Ke, P.C.; Kadonaga, J.T.; Smith, D.E. Forced unraveling of nucleosomes assembled on heterogeneous DNA using core histones, NAP-1, and ACF. J. Mol. Biol. 2005, 351, 89-99.

42. Roopa, T.; Shivashankar, G.V. Direct measurement of local chromatin fluidity using optical trap modulation force spectroscopy. Biophys. J. 2006, 91, 4632-4637.

43. Shundrovsky, A.; Smith, C.L.; Lis, J.T.; Peterson, C.L.; Wang, M.D. Probing SWI/SNF remodeling of the nucleosome by unzipping single DNA molecules. Nat. Struct. Mol. Biol. 2006, 13, 549-554.

44. Mihardja, S.; Spakowitz, A.J.; Zhang, Y.; Bustamante, C. Effect of force on mononucleosomal dynamics. Proc. Natl. Acad. Sci. USA 2006, 103, 15871-15876. 
45. Zhang, Y.; Smith, C.L.; Saha, A.; Grill, S.W.; Mihardja, S.; Smith, S.B.; Cairns, B.R.; Peterson, C.L.; Bustamante, C. DNA translocation and loop formation mechanism of chromatin remodeling by SWI/SNF and RSC. Mol. Cell 2006, 24, 559-568.

46. Lia, G.; Praly, E.; Ferreira, H.; Stockdale, C.; Tse-Dinh, Y.C.; Dunlap, D.; Croquette, V.; Bensimon, D.; Owen-Hughes, T. Direct observation of DNA distortion by the RSC complex. Mol. Cell 2006, 21, 417-425.

47. Hall, M.A.; Shundrovsky, A.; Bai, L.; Fulbright, R.M.; Lis, J.T.; Wang, M.D. High-resolution dynamic mapping of histone-DNA interactions in a nucleosome. Nat. Struct. Mol. Biol. 2009, 16, 124-129.

48. Bussiek, M.; Hoischen, C.; Diekmann, S.; Bennink, M.L. Sequence-specific physical properties of African green monkey alpha-satellite DNA contribute to centromeric heterochromatin formation. J. Struct. Biol. 2009, 167, 36-46.

49. Hodges, C.; Bintu, L.; Lubkowska, L.; Kashlev, M.; Bustamante, C. Nucleosomal fluctuations govern the transcription dynamics of RNA polymerase II. Science 2009, 325, 626-628.

50. Ran, S.-Y.; Wang, X.-L.; Fu, W.-B.; Lai, Z.-H.; Wang, W.-C.; Liu, X.-Q.; Mai, Z.-H.; Li, M. Direct observation of histone-induced DNA shortening. Chin. Phys. Lett. 2006, 23, 504-507.

51. Ran, S.-Y.; Wang, X.-L.; Fu, W.-B.; Wang, W.-C.; Li, M. Single molecule DNA compaction by purified histones. Chin. Sci. Bull. 2008, 53, 836-841.

52. Yan, J.; Maresca, T.J.; Skoko, D.; Adams, C.D.; Xiao, B.; Christensen, M.O.; Heald, R.; Marko, J.F. Micromanipulation studies of chromatin fibers in Xenopus egg extracts reveal ATPdependent chromatin assembly dynamics. Mol. Biol. Cell 2007, 18, 464-474.

53. Bancaud, A.; Wagner, G.; Conde, E.S.N.; Lavelle, C.; Wong, H.; Mozziconacci, J.; Barbi, M.; Sivolob, A.; Le Cam, E.; Mouawad, L.; Viovy, J.L.; Victor, J.M.; Prunell, A. Nucleosome chiral transition under positive torsional stress in single chromatin fibers. Mol. Cell 2007, 27, 135-1347.

54. Kruithof, M.; Chien, F.; de Jager, M.; van Noort, J. Subpiconewton dynamic force spectroscopy using magnetic tweezers. Biophys. J. 2008, 94, 2343-2348.

55. Kruithof, M.; Chien, F.T.; Routh, A.; Logie, C.; Rhodes, D.; van Noort, J. Single-molecule force spectroscopy reveals a highly compliant helical folding for the $30-\mathrm{nm}$ chromatin fiber. Nat. Struct. Mol. Biol. 2009, 16, 534-540.

56. Kruithof, M.; van Noort, J. Hidden Markov analysis of nucleosome unwrapping under force. Biophys. J. 2009, 96, 3708-3715.

57. Gupta, P.; Zlatanova, J.; Tomschik, M. Nucleosome assembly depends on the torsion in the DNA molecule: A Magnetic Tweezers study. Biophys. J. 2009, 97, 3150-3157.

58. Leuba, S.; Zlatanova, J.; Karymov, M.A.; Bash, R.; Y.-Z.L.; Lohr, D.; Harrington, R.E.; Lindsay, S. The mechanical properties of single chromatin fibers under tension. Single Mol. 2000, 1, 185-192.

59. Leuba, S.H.; Karymov, M.A.; Liu, Y.; Lindsay, S.M.; Zlatanova, J. Mechanically stretching single chromatin fibers. Gene Ther. Mol. Biol. 1999, 4, 297-301.

60. De Lucia, F.; Alilat, M.; Sivolob, A.; Prunell, A. Nucleosome dynamics. III. Histone taildependent fluctuation of nucleosomes between open and closed DNA conformations. Implications for chromatin dynamics and the linking number paradox. A relaxation study of mononucleosomes on DNA minicircles. J. Mol. Biol. 1999, 285, 1101-1119. 
61. Sivolob, A.; Lavelle, C.; Prunell, A. Sequence-dependent nucleosome structural and dynamic polymorphism. Potential involvement of histone $\mathrm{H}_{2} \mathrm{~B}$ N-terminal tail proximal domain. J. Mol. Biol. 2003, 326, 49-63.

62. Sivolob, A.; Prunell, A. Nucleosome conformational flexibility and implications for chromatin dynamics. Philos. Trans. A: Math. Phys. Eng. Sci. 2004, 362, 1519-1547.

63. Zlatanova, J.; Bishop, T.C.; Victor, J.M.; Jackson, V.; van Holde, K. The nucleosome family: Dynamic and growing. Structure 2009, 17, 160-171.

64. Hamiche, A.; Carot, V.; Alilat, M.; De Lucia, F.; O'Donohue, M.F.; Revet, B.; Prunell, A. Interaction of the histone (H3-H4) 2 tetramer of the nucleosome with positively supercoiled DNA minicircles: Potential flipping of the protein from a left- to a right-handed superhelical form. Proc. Natl. Acad. Sci. USA 1996, 93, 7588-7593.

65. Lankas, F.; Sponer, J.; Hobza, P.; Langowski, J. Sequence-dependent elastic properties of DNA. J. Mol. Biol. 2000, 299, 695-709.

66. Ben-Haim, E.; Lesne, A.; Victor, J.M. Chromatin: A tunable spring at work inside chromosomes. Phys. Rev. E: Stat. Nonlin. Soft Matter Phys. 2001, 64, 051921:1-051921:19.

67. Wedemann, G.; Langowski, J. Computer simulation of the 30-nanometer chromatin fiber. Biophys. J. 2002, 82, 2847-2859.

68. Deufel, C.; Forth, S.; Simmons, C.R.; Dejgosha, S.; Wang, M.D. Nanofabricated quartz cylinders for angular trapping: DNA supercoiling torque detection. Nat. Methods 2007, 4, 223-225.

69. Mosconi, F.; Allemand, J.F.; Bensimon, D.; Croquette, V. Measurement of the torque on a single stretched and twisted DNA using magnetic tweezers. Phys. Rev. Lett. 2009, 102, 078301:1-078301:4.

70. Celedon, A.; Nodelman, I.M.; Wildt, B.; Dewan, R.; Searson, P.; Wirtz, D.; Bowman, G.D.; Sun, S.X. Magnetic tweezers measurement of single molecule torque. Nano Lett. 2009, 9, 1720-1725.

71. Lu, Y.; Weers, B.; Stellwagen, N.C. DNA persistence length revisited. Biopolymers 2001, 61, 261-275.

72. Hagerman, P.J. Flexibility of DNA. Annu. Rev. Biophys.: Biophys. Chem. 1988, 17, 265-286.

73. Ringrose, L.; Chabanis, S.; Angrand, P.O.; Woodroofe, C.; Stewart, A.F. Quantitative comparison of DNA looping in vitro and in vivo: Chromatin increases effective DNA flexibility at short distances. Embo J. 1999, 18, 6630-6641.

74. Dekker, J.; Rippe, K.; Dekker, M.; Kleckner, N. Capturing chromosome conformation. Science 2002, 295, 1306-1311.

75. Bystricky, K.; Heun, P.; Gehlen, L.; Langowski, J.; Gasser, S.M. Long-range compaction and flexibility of interphase chromatin in budding yeast analyzed by high-resolution imaging techniques. Proc. Natl. Acad. Sci. USA 2004, 101, 16495-16500.

76. Fujimoto, B.S.; Schurr, J.M. Dependence of the torsional rigidity of DNA on base composition. Nature 1990, 344, 175-177.

77. Shore, D.; Baldwin, R.L. Energetics of DNA twisting. I. Relation between twist and cyclization probability. J. Mol. Biol. 1983, 170, 957-981.

78. Neukirch, S. Extracting DNA twist rigidity from experimental supercoiling data. Phys. Rev. Lett. 2004, 93, 198107:1-198107:4. 
79. Cluzel, P.; Lebrun, A.; Heller, C.; Lavery, R.; Viovy, J.L.; Chatenay, D.; Caron, F. DNA: An extensible molecule. Science 1996, 271, 792-79.

80. Smith, S.B.; Cui, Y.; Bustamante, C. Overstretching B-DNA: The elastic response of individual double-stranded and single-stranded DNA molecules. Science 1996, 271, 795-799.

81. Wang, M.D.; Yin, H.; Landick, R.; Gelles, J.; Block, S.M. Stretching DNA with optical tweezers. Biophys. J. 1997, 72, 1335-1346.

82. Katritch, V.; Bustamante, C.; Olson, W.K. Pulling chromatin fibers: Computer simulations of direct physical micromanipulations. J. Mol. Biol. 2000, 295, 29-40.

83. Dorigo, B.; Schalch, T.; Kulangara, A.; Duda, S.; Schroeder, R.R.; Richmond, T.J. Nucleosome arrays reveal the two-start organization of the chromatin fiber. Science 2004, 306, 1571-1573.

84. Wong, H.; Victor, J.M.; Mozziconacci, J. An all-atom model of the chromatin fiber containing linker histones reveals a versatile structure tuned by the nucleosomal repeat length. PLOS ONE 2007, 2, e877.

85. Cairns, B.R. Chromatin remodeling: Insights and intrigue from single-molecule studies. Nat. Struct. Mol. Biol. 2007, 14, 989-996.

86. Joo, C.; Balci, H.; Ishitsuka, Y.; Buranachai, C.; Ha, T. Advances in single-molecule fluorescence methods for molecular biology. Annu. Rev. Biochem. 2008, 77, 51-76.

87. Kanger, J.S.; Subramaniam, V.; van Driel, R. Intracellular manipulation of chromatin using magnetic nanoparticles. Chromosome Res. 2008, 16, 511-522.

88. De Vries, A.H.; Krenn, B.E.; van Driel, R.; Subramaniam, V.; Kanger, J.S. Direct observation of nanomechanical properties of chromatin in living cells. Nano Lett. 2007, 7, 1424-1427.

(C) 2010 by the authors; licensee Molecular Diversity Preservation International, Basel, Switzerland. This article is an open-access article distributed under the terms and conditions of the Creative Commons Attribution license (http://creativecommons.org/licenses/by/3.0/). 